\title{
LA ESCENOGRAFÍA \\ EN EL TEATRO DE MANUEL LINARES RIVAS: \\ EL ESPACIO Y EL TIEMPO
}

\author{
Gabriel Ares Cuba \\ Universidade da Coruña
}

\section{RESUMEN}

En este artículo se analizan algunos de los ambientes más significativos en la obra teatral de Manuel Linares Rivas. El principal objetivo es aportar una primera sugerencia de clasificación de sus espacios y valorar hasta qué punto el autor los utiliza como transmisores de su compromiso social. Se sostiene que la construcción escénica arroja luz sobre la probable filiación de Linares Rivas a una tendencia novadora y rupturista del teatro del primer tercio del siglo $\mathrm{xx}$.

Palabras Clave: teatro siglo $\mathrm{xx}$, espacio teatral, tiempo teatral, teatro social, símbolos teatrales.

\author{
SCENOGRAPHY \\ IN MANUEL LINARES RIVAS' DRAMA: \\ SPACE AND TIME
}

\section{Abstract}

In this paper, I have analyzed some of the most significant spaces in Manuel Linares Rivas' dramatical work. The main purpose is to suggest a first clasification of their spaces. Also, I have valued the social commitment contained in them. I argue that the stage construction could clarify the probable affiliation of Linares Rivas to a new trend in the drama of the first third of the 20th century.

KEYwORDs: 20th-century drama, theatrical space, theatrical time, social drama, theatrical symbols. 
Manuel Linares Rivas (1866-1938) pertenece a una larga lista de autores que gozaron de un gran éxito y prestigio en su momento, pero a los que las circunstancias históricas acabaron por condenar al ostracismo. A este autor le acompaña un estigma de forma recurrente, que es el ser considerado un continuador de la técnica teatral de Jacinto Benavente (1866-1954). José García López (1962), Max Aub (1974) y Gerald Brown (1974) son los primeros en realizar esta filiación, que será discutida unos años más tarde por Ángel Berenguer (1982). A él se le debe el primer intento por diferenciar las distintas corrientes teatrales de este periodo: teatro restaurador (representante de la perspectiva de la nobleza y que aboga por restaurar los valores tradicionales), teatro innovador (perspectiva de la burguesía acomodada en connivencia con la nobleza y el clero, pero presentando intentos de modernización hacia el liberalismo mediante nuevas técnicas teatrales) y teatro novador (visión de la burguesía radical en consonancia con los intereses pequeñoburgueses y obreros, igualmente mediante la modernización dramatúrgica). Berenguer sitúa a Benavente dentro del teatro innovador, pero a Linares Rivas, dentro del teatro novador, quedando alineado con autores como Benito Pérez Galdós (1843-1920), Joaquín Dicenta (1862-1917), Ángel Guimerá (1845-1924) o Ramón Gómez de la Serna (1888-1963).

Más adelante, sin embargo, Francisco Ruiz Ramón (1986) rescatará la visión original. A partir de aquí, comienza una polémica todavía hoy sin resolver. Autores como Alfredo Rodríguez López-Vázquez (1995), Fidel López Criado (1999, 2014), Moisés Castro (2008), Rebeca Díez Figueroa (2005), Ana María García Freire (2009), José María Villarías Zugazagoitia (2001) o José Carlos Mainer (2010) apoyan la tesis de Berenguer y desvinculan a Linares Rivas de la tendencia innovadora. Al contrario, autores como Huerta Calvo y Peral Vega (2003) o Lina Rodríguez Cacho (2009) apoyan los preceptos de Ruiz Ramón.

En este trabajo se intentará responder las siguientes preguntas: ¿qué tipos de espacio presentan las obras de Linares Rivas? ¿¿Hasta qué punto se transmite un compromiso social a través de la escenografía? Se partirá de la hipótesis que sostiene su filiación a la tendencia novadora, que representa la perspectiva de la burguesía radical en contra del pacto entre burguesía y nobleza. De esta forma, sus espacios se distanciarían del sistema de valores que había sustentado la II Restauración borbónica.

\section{ESPACIOS BURGUESES}

Estos espacios constan de salones modernos y prácticos, propios de una nueva generación que se ha ido deshaciendo de las anticuadas pertenencias de sus antepasados para dar lugar a una nueva forma de vida. Quizá sea este el ambiente más socorrido por Linares Rivas. Un ejemplo que ilustra este tipo de espacios es Cobardias, comedia en dos actos y en prosa, estrenada en el Teatro Lara el 15 de enero de $1919^{1}$.

\footnotetext{
${ }^{1}$ Otras obras cuyos espacios podrían encajar en esta etiqueta podrían ser Aire de fuera, comedia en tres actos estrenada en el Teatro Español el 31 de marzo de 1903; o En cuarto creciente,
} 
La escenografía del primer acto consta de «una salita relativamente modesta, pero con buenos muebles antiguos, retratos y cuadros» (Linares Rivas 1919: 7), la casa de Matilde. La sala es «relativamente modesta» porque la familia no recibe ingresos. Esto se refleja en esos «muebles antiguos» que decoran la sala, como elementos del pasado que atormentan la anticuada mentalidad de la familia, demasiado apegada a su abolengo como para modernizar sus costumbres. «Es de día, por la tarde, en octubre» (Linares Rivas 1919: 7). Esta acotación temporal denota la escena como un momento en decadencia, a punto de terminar el día y en otońo, cuando caen las hojas de los árboles y el año llega a su fin. Es el final de la era de la nobleza.

En cambio, la escenografía del segundo acto es «una salita-gabinete-despacho-escritorio... ¡tiene de todo!, pero todo bueno» (Linares Rivas 1919: 55). Es la misma casa de Matilde, pero transformada gracias a la presencia de Figueredo después del enlace con Cecilia. Cecilia, que había sido educada bajo los preceptos de la nobleza, ahora lleva las cuentas de la tienda de Figueredo. Su comportamiento se ha vuelto burgués siguiendo el ejemplo de su esposo, que había sacrificado tanto para alcanzar esa posición. Aquellos «muebles antiguos» han dejado paso a una habitación funcional, que sirve tanto para trabajar como para leer o descansar. «Es invierno, anochecido" (Linares Rivas 1919: 55). Estas indicaciones temporales denotan un momento de cambio, de renacimiento. El paso de una decoración a otra es metáfora de la agonía de la nobleza ante el auge de la burguesía ${ }^{2}$.

Linares Rivas ya aborda estos espacios desde el principio de su carrera, desde que estrena el 23 de febrero de 1891 en el Teatro de la Princesa El camino de la gloria, su primera obra conservada. En ella, los espacios están preparados para que todos los personajes puedan estar en la escena al mismo tiempo, lo que en su momento supuso un contraste con los espacios neorrománticos. Esto podría esperarse del decorado del primer acto («un saloncito de una casa de buen tono» [Linares Rivas 1999d: 925]), pero resulta más extraño el caso del tercer acto, donde «la escena representa el despacho del señor Rojas» (Linares Rivas 1999d: 954). Linares Rivas se enfrenta así al individualismo burgués. Los espacios están fuertemente conectados con el comportamiento de su protagonista. En el primer acto, el abogado se sentía cómodo viviendo en sociedad. En el segundo acto, ambientado en «una sala en casa de los señores de Rojas» (Linares Rivas 1999d: 941), el protagonista vive aquejado por su problema familiar. Finalmente, en el tercer acto solo se preocupa por su estabilidad emocional. A medida que Rojas se va haciendo introvertido, los espacios se van cerrando.

juguete cómico en un acto estrenado en el Teatro Lara el 11 de noviembre de 1905. La primera abre con «decoración de saloncito elegante que servirá para los otros dos actos» (Linares Rivas 1999: 1069). Este minimalismo escénico presente en Aire de fuera contrasta con el horror vacui de En cuarto creciente: «un gabinete de confianza. Sillería, sofá, butacas, sillas volantes. Muebles modernistas. Alfombras. Aparato de luz eléctrica, apagado. Es de día» (Linares Rivas 1928: 7). Para un análisis pormenorizado de esta obra, véase el artículo de Alfredo Rodríguez LópezVázquez (1994).

${ }^{2}$ La obra quiere mostrar la decadencia moral de la sociedad española de principios del siglo xx siguiendo la línea regeneracionista. Sin embargo, hay que destacar que la modernidad que Figueredo lleva a la familia de Cecilia no soluciona el problema, por eso la obra termina de forma trágica. 


\section{ESPACIOS ARISTOCRÁTICOS}

Estos ambientes son los propios de la nobleza más reaccionaria que todavía conservaba su tradicional relevancia en el país durante el primer tercio del siglo xx. En cierto modo, se podría decir que el primer acto de Cobardías se enmarca en un ambiente propio de la nobleza, pero de una nobleza sin poder. En cambio, la escenografía de La garra muestra toda la enjundia de la aristocracia rural gallega ${ }^{3}$. La garra, drama en dos actos, es estrenada el 21 de diciembre de 1914 en el Teatro de la Princesa ${ }^{4}$.

La trama se sitúa en Campanela, trasunto de Santiago de Compostela, ciudad natal del autor, tal y como indica la acotación inicial: «La acción en Campanela, una ciudad que vive muerta, como Brujas, como Salamanca, como Toledo, como Santiago...» (Linares Rivas 1999h: 1917). Linares Rivas localiza la historia en una ciudad ficticia que permite aplicar toda la crítica a todas aquellas ciudades que «viven muertas», aquellas cuyos habitantes se niegan a avanzar aferrándose a las tradiciones y a los mandatos de la Iglesia y la ley. El personaje que mejor explica el significado de Campanela es Álvaro:

Campanela es tu enemigo... y el mío. Créeme, Santa; deja una ciudad que llora siempre con el agua de sus lluvias... que gime diariamente con el monótono son de sus campanas... que conserva gustosa los viejos caserones y los muebles viejos. Créeme, Santa: deja una ciudad que ama las nubes durante el día y los fantasmas durante la noche y elige una ciudad que goce en la luz y en el bullicio y que ame la alegría, que es el único bien de los mortales (Linares Rivas 1999h: 1954).

Álvaro describe la vida en Campanela como un ejercicio de esclavitud y amargura. Las gentes de esta ciudad siempre están llorando ("ÁLVA. - Llueve. SANTA. - Como siempre en Campanela...» [Linares Rivas 1999h: 1925]), constantemente sobrecogidas por el llamamiento a las misas y excesivamente preocupadas por las viejas tradiciones. Escapan del sol, metáfora de felicidad y de verdad, siguiendo la costumbre austera del enclaustramiento religioso. La noche, momento perfecto para el esparcimiento

3 Otra obra que se ambienta en espacios aristocráticos es Primero, vivir..., comedia en tres actos, estrenada en el Teatro de la Princesa el 16 de enero de 1926. Abre con «un interior muy confortable en casa de los condes de Casa-Prau, en Madrid» (Linares Rivas 1927: 79). La escenografía final es determinante: «la misma decoración, que en los actos anteriores tuvo el foro de ventanas cerradas y ahora aparecen abiertas, a toda luz de una tarde hermosa de mayo" (Linares Rivas 1927: 116). Aparece la ventana como signo de transformación, que trae la luz del sol (verdad) y el aire de fuera (cambios sociales). No en vano, en el tercer acto se resuelve el conflicto dramático en contra de los condes. Es interesante el contraste con La garra, ya que presenta un mismo tipo de espacio, pero mediante su tan característico minimalismo.

${ }^{4}$ López Criado recuerda que «las iras del clero y del sector más involucionista de la burguesía no se hicieron esperar en la recepción crítica de La garra. Pero tampoco se hicieron esperar las simpatías del proletariado y la pequeña burguesía. [...]. Desde entonces, La garra pasaría a ser símbolo de todo aquello que la España de la Santa Tradición debía combatir como nocivo, foráneo, antipatriótico y anticristiano en el teatro» (López Criado 2009: 35). 
íntimo en la alcoba, la dedican amando los fantasmas, que no es otra cosa que los miedos infundados por la Iglesia a la práctica sexual sin intención de procrear. Álvaro le aconseja a Santa que elija una ciudad laica ("que goce en la luz»), cosmopolita ("y en el bullicio») y que no castigue los actos de amor ("y que ame la alegría»).

La escenografía del interior es la misma en ambos actos:

Una gran sala, en un gran caserón, alta de techos, recia de muros y con fuertes puertas de nogal labrado. Las colgaduras fueron chillonas, pero el tiempo ha suavizado el color; los muebles, con el clásico estrado, son amplios, sólidos y ricos; los cuadros, pocos, grandes y de asunto religioso, tienen el fondo oscuro y el oro de los marcos apagado; sobre una mesa, de tablero de mármol, la reproducción en marfil de un crucero de caminos con cuatro gradas, el grupo de la Dolorosa con Cristo yacente en el regazo, y luego la cruz de brazos anchos y cortos; una pequeña vitrina y objetos de cristal. En el testero un retrato grande del cardenal Espiñeira, primo de los señores de la casa, y actual prelado de Campanela. En un ángulo otra vitrina grande. El piso es de madera; sobre la alfombra un brasero de bronce. Una gran araña de cristal, centrada de velas y que no se encenderá. Unas luces eléctricas que contrastan, por lo mismo que son elegantes y modernas, con el tono austero y mohoso de la sala. La comodidad, venciendo y arrinconando a la severidad, demuestra una vez más que todo tiempo pasado fue peor... Es de noche; en abril. Llueve (Linares Rivas 1999h: 1919).

El escenario muestra una sala propia de la nobleza. No solo es una «gran sala» en un "gran caserón", sino que tiene un techo alto sustentado por paredes fuertes y con "puertas de nogal labrado». Es una casa de lujo lastrada por el paso del tiempo, con una mueblería también gastada, en la que destaca la colocación de un "clásico estrado», tarima que limitaba la presencia femenina durante algunos actos sociales con el fin de separar ambos sexos. Esto denotará la actitud de los personajes con respecto a la sexualidad, que, salvo Álvaro del Real y el marqués de Montrove, coincide con los preceptos de la Iglesia. Cabe decir también que durante el siglo XIX este estrado empezó a caer en desuso, con lo cual en 1914 ya estaba obsoleto. Los cuadros denotan la constante presencia de la Iglesia 5 . Tienen el fondo oscuro y el marco apagado, lo que supone una crítica abierta a la estructura ideológica que sustenta el poder del clero. Suponiéndose en el centro de la escena, se sitúa la mesa de mármol y, sobre ella, un crucero tallado en marfil, el grupo de la Dolorosa y Cristo yacente y una cruz de brazos cortos y anchos. El mármol y el marfil vuelven a denotar una posición social elevada. El crucero es una figura especialmente relevante para Galicia, al igual que la cruz, reminiscencia de la antigua provincia de Santiago que fue absorbida por la provincia de A Coruña en 1833. El grupo de la Dolorosa y Cristo denota la amargura, el dolor y la angustia que se palpa en el ambiente, pero también, aunque en menor medida, la piedad (la Virgen de los Dolores también es

5 En esta obra se retrata la enorme influencia de la Iglesia sobre las leyes del país. Linares Rivas denuncia «la ausencia de humanidad y sensibilidad en la aplicación literal de la ley por parte de los tribunales» (Castaño Penalva 2015: 71), como haría más tarde Clara Campoamor. 
conocida como la Virgen de la Amargura, la Virgen de las Angustias y la Virgen de la Piedad). Las vitrinas denotan, nuevamente, poderío económico, mientras que el destacado cuadro del cardenal Espiñeira redunda en la idea de la presencia clerical.

El suelo de madera, la alfombra y el brasero de bronce son también signos que señalan la posición social. Normalmente, las casas gallegas no tenían suelo de construcción, se pisaba directamente sobre la tierra. Por supuesto, una alfombra es considerada un gasto innecesario, mientras que el brasero, sobre todo siendo de bronce, era un bien necesario e inalcanzable para los más desfavorecidos. Lo mismo cabe decir de la lámpara de araña y de la presencia de luz eléctrica, elemento de lujo, sobre todo en Galicia. Sin embargo, lejos de iluminar la sala, lo que hace es acentuar su «tono austero y mohoso».

Por último, se indica que la familia se resiste a abandonar los elementos tradicionales de la casa, pero se enfrentan a su necesidad por estar cómodos. Esto es una metáfora: la generación más anciana de la casa (Esperanza, Tirso, el cardenal, etc.) quiere seguir viviendo en la «severidad», pero la más joven (Sol, Santa, Antonio, etc.) desea alcanzar la "comodidad». La casa es testigo del cambio generacional demostrando que "todo tiempo pasado fue peor". Es de noche, signo que anuncia la celebración del baile de disfraces. Es abril, es primavera, la estación del amor, del cambio, del sexo. Sin embargo, llueve, y, tal y como había dicho Álvaro, Campanela es "una ciudad que llora siempre con el agua de sus lluvias» (Linares Rivas 1999h: 1954).

Durante la escena I del acto primero se muestra la siguiente ambientación: «Tadea y Úrsula, sentadas en sillitas de paja, cosen los capuchones y los antifaces. A su lado otra silla pequeña, con un traje de máscara, abandonado sobre el asiento como si alguien hubiera dejado momentáneamente la labor» (Linares Rivas 1999h: 1919). Las sillitas de paja eran la novedad dentro del movimiento decimonónico arts and crafts, que pretendía recuperar la forma medieval artesanal de construir muebles. Este estilo nace en las últimas décadas del siglo xix y es contemporáneo al modernismo. Sin embargo, se diferencian fundamentalmente en que aquel centra su mirada en las formas del pasado, mientras que este procura abrir otros horizontes.

El tratamiento del espacio en esta obra es cercano al naturalista: el entorno construye al individuo. De esta manera, si una persona vive en Campanela, se comportará como un habitante de allí; mientras que, si viaja a Madrid, cambiará de actitud conforme a lo «natural» del madrileño. Sin embargo, el marqués de Montrove, Álvaro del Real y el padre Muińos logran vencer este determinismo gracias a su pensamiento crítico y rupturista. No obstante, esto los conducirá a un final trágico: el marqués interrumpe voluntariamente su vida, Álvaro abandona Campanela y Muiños probablemente será excomulgado de nuevo al absolver los pecados de Antonio en el momento de su suicidio ${ }^{6}$.

${ }^{6}$ El ideario de Linares Rivas no le permitía comulgar con el determinismo. En Aire de fuera (1903), Eduardo, Gerardo y Gregorio discuten con Baltasar la pertinencia de la ley de divorcio. Baltasar argumenta que es la mujer la gran víctima de esta ley inhumana que impide a los cónyuges 


\section{ESPACIOS RURALES}

Aunque es cierto que La garra se ambienta en una ciudad trasunto de Santiago de Compostela, no parece que su construcción espacial corresponda con un entorno rural. No obstante, Manuel Linares Rivas, igual que sus coetáneos Jacinto Benavente o Ángel Guimerá, cultivará el drama rural en obras como Cristobalón (1920) o El alma de la aldea (1924)7. Pero la obra que aquí nos ocupa es La mala ley, comedia en tres actos estrenada en el Teatro Lara el 21 de febrero de 1923.

La trama tiene lugar "por tierras de Ponferrada, hacia la raya de Galicia» (Linares Rivas 1927: 2). En primer lugar, hay que destacar la imprecisión geográfica, característica muy común dentro de los dramas rurales. Esto le confiere a la acción un aura de lejanía y misterio para que los espectadores de las ciudades entendiesen la desigualdad entre la ciudad y el campo. La razón de situar la obra en algún lugar de Ponferrada responde a la escasa industrialización de la zona, que tradicionalmente se sustentó gracias al sector agrícola. Por otro lado, el hecho de que esté cerca de la «raya de Galicia» alude al sentimiento galleguista que experimentaba el autor hacia su tierra natal ${ }^{8}$.

El espacio interior es «una sala, con muebles antiguos, castellanos, en la casa-palacio de los seńores de la Hermida. Una gran ventana abierta» (Linares Rivas 1927: 5). La acotación es mucho menos detallada que en La garra, Linares Rivas abandona el horror vacui y construye una sala con espacios vacíos. Los «muebles antiguos", que en La garra se mostraban lujosos y decadentes, aquí se refieren a la humildad de unos señores del campo que no reciben los suficientes beneficios de sus tierras como para modernizar su mueblería. El autor decide ceñirse al canon de su tiempo y decora la sala con muebles "castellanos», en alusión al lugar común literario más corriente en el primer tercio del siglo xx. La «gran ventana abierta»

separarse definitivamente y encontrar el amor en otra persona, a lo que contestan: «EduA. Pero las costumbres... BALt. Ya cambian ellas. Edua. Y las leyes... Balt. Las podemos cambiar nosotros. [...] Greg. Aquí hay muchas preocupaciones arraigadísimas. BALt. Y duendes y fantasmas... ¿Quieres conservarlos? Edua. Nosotros no lo hemos de cambiar. BaLt. Sí, sí, nosotros. Y los felices, los dichosos, con más razón, mejor dicho, con más deber» (Linares Rivas 1999e: 1077).

7 Tampoco es posible olvidar Mal año de lobos, comedia en tres actos estrenada en el Teatro Lara el 27 de octubre de 1927. La trama se ambienta en «una casa de aldeanos acomodados. Planta baja. Al foro, a un lado, una puerta que se abre en dos mitades, quedando generalmente cerrada la de abajo, con un picaporte que se abre con facilidad desde fuera también, cuando está abierta la mitad superior. Una ventana. Muebles de madera y cuerda. A un lado, un arcón grande. En el centro, una mesa. Sobre ella desciende una bombilla eléctrica con una sencillísima pantalla de papel» (Linares Rivas 1999: 2307). Como puede verse, Linares opta aquí por un realismo escénico más acentuado que en La mala ley. Nuevamente aparece una ventana cerrada que indica una posibilidad de cambio. Esta gran casa está avejentada, lo que indica que pertenece a grandes propietarios venidos a menos, como en La mala ley.

${ }^{8}$ Así hablaba Linares Rivas en su discurso de ingreso a la Real Academia Española: «alabé a Curros, sí, pero en el fondo de mi alma estoy alabando a Galicia. Me conmueven sus versos, sí, pero en lo más apegado del corazón está mi propia morriña, que nace siempre de sus recuerdos un verso más...» (Linares Rivas 1921: 31-32). 
no tiene utilidad para la realización del espectáculo, pero sí tiene carga simbólica. Si La garra presentaba un espacio claustrofóbico, La mala ley muestra un espacio fresco a través de la entrada de aire por la ventana. Es una metáfora muy recurrente en Linares Rivas en que se asimila el aire de fuera con el progreso.

Según la localización temporal, «es de día, por la tarde y en junio» (Linares Rivas 1927: 5). Los otros dos actos mantienen la misma decoración, pero avanzan temporalmente. En el segundo acto "es por la mañana del día siguiente» (Linares Rivas 1927: 31) y en el tercero "es por la tarde y al día siguiente» (Linares Rivas 1927: 57). Este juego de luces provoca una sensación de circularidad en la trama; además, sitúa el acto segundo en un momento en que el sol, como metáfora de verdad o de justicia, alumbra la conciencia de los personajes protagonistas. De hecho, es en el segundo acto cuando Lorenzo de la Hermida enuncia el significado central de la obra: «que hereden, sí, muy bien...; pero que hereden a los muertos y no a los que aún viven; que eso no es heredar, sino despojar. Y la ley inicua, la mala ley es la que otorga derecho para reclamar la herencia de los padres mientras uno de ellos vive todavía» (Linares Rivas 1927: 53).

La acción tiene lugar durante el mes de junio. Para entender esta referencia temporal es preciso tener en cuenta el siguiente fragmento de la conversación inicial entre Saturio, uno de los trabajadores, y Lorenzo de la Hermida:

SATU. - Se irá. Y también traigo un mandao del señor cura, para ver si le dejan este domingo una casulla encarnada, que la necesita porque...

Loren. -Cállatelo también. Capilla, casa y administración general, todo eso es del reino de Cristina.

SATU. - ¿Y a la señorita con el cuento del cura?

Loren. - A ella..., si no es verde.

SATU. - No, es encarnada (Linares Rivas 1927: 6).

Visto este fragmento, cabe preguntarse por qué necesita el cura una casulla precisamente encarnada. Los colores de las casullas los regula la Institución General del Misal Romano, vinculándoles una serie de festividades. La única que encaja en el contexto de la obra es el domingo de Pentecostés, que se celebra el 9 de junio y marca el inicio de las actividades de la Iglesia católica. No en vano, supone la fiesta más importante para el catolicismo después de la celebración de la Pascua. Lo que resulta curioso es que la ruptura de la familia de Lorenzo se manifieste justamente cuando la Iglesia retoma sus labores. Según el planteamiento de Linares Rivas, la Iglesia se opone a la constitución de la familia, al igual que había sucedido, aunque de manera más contundente, en La garra.

\section{ESPACIOS POPULARES}

En pocas ocasiones Linares Rivas cultiva los ambientes de la pobreza. Esto se debe fundamentalmente a que, según él, el teatro debe ser expresión de las experiencias conocidas, hasta tal punto que reconoce sentirse incapaz de hacer hablar 
con naturalidad a personajes de bajo estrato social ${ }^{9}$. Sin embargo, en La espuma del champagne logra dar verosimilitud a las acciones dramatizadas gracias a que consigue mantener su punto de vista como burgués crítico y desencantado con el mundo que le tocó vivir ${ }^{10}$. La espuma del champagne, comedia en cuatro actos y en prosa, se estrena en el Teatro Eslava el 18 de marzo de $1915^{11}$.

La escena abre con «una habitación muy modesta, pobre. Puerta izquierda y puerta al foro, a izquierda también; a derecha foro una ventana sobre tejados. A lateral derecha otra ventana; al lado una mesita de costura. Tres o cuatro sillas y una consola vieja. Una mesa. Luz eléctrica colgante, sin tulipa» (Linares Rivas 1999: 1973). Lo primero que llama la atención es que Linares Rivas opte por especificar una iluminación de la escena que provenga de una bombilla teniendo en cuenta que la sala tiene dos ventanas. Por un lado, hay que recordar que el signo de la ventana en Linares Rivas suele significar un cambio profundo hacia el progreso social, pero en este caso las ventanas están cerradas e inutilizadas, no sirven para que entre el aire ni la luz. Es decir, que Linares Rivas está indicando que en una habitación pobre existen grandes posibilidades de cambio (hay dos ventanas, una de ellas sobre tejados), pero los personajes que allí moran las ignoran. Por otro lado, la luz eléctrica colgante dará pie a mostrar que en el país existe un desarrollo tecnológico suficiente para surtir de ciertas comodidades a un número razonable de ciudadanos, pero que para los colectivos marginalizados las facturas son imposibles de pagar $^{12}$. Se nos muestra también una mesita de costura en la que Sebastiana se encuentra cosiendo («después de coser un momento en ropa blanca, queda absorta, sonríe, y saca del pecho una carta» [Linares Rivas 1999i: 1973]), lo que augura su situación como trabajadora de costura por cuenta propia ganando un salario miserable, de lo que dan cuenta los muebles viejos y humildes. "Es de día, pero anocheciendo ya», lo que permite suponer que la acción de la obra continuará por la noche, aunque también simboliza la decadencia material de Sebastiana.

El segundo acto se ambienta en «una habitación puesta con lujo, pero con desorden, en la casa de la Rabanitos» (Linares Rivas 1999i: 1982). La "Rabanitos» había sido compañera de escuela de Sebastiana, habían crecido juntas en un entorno de miseria. Sin embargo, a la «Rabanitos» le rodea el lujo recogido de su trabajo

${ }^{9}$ En una de sus charlas, Linares dice lo siguiente: «tanto es así, poniendo el ejemplo en mí mismo, que yo suelo acertar en las comedias... y desacierto en cuanto voy al sainete. No sé hacer hablar a la gente del pueblo, mi manera de decir no es la suya y disuenan mis palabras en sus labios» (Linares Rivas 1999a: 233).

${ }^{10}$ Linares Rivas dijo en una ocasión: «para muchos no es interesante lo que no redunda en su propio beneficio; para muchos es incomprensible que alguien se afane por un afán ajeno; y para muchos también, que tienen resuelto el problema de su vida, les parece absurdo que se plantee el problema de la vida de otros..." (Linares Rivas 1999b: 252).

${ }^{11}$ Existe una versión anterior de esta obra publicada en El Cuento Semanal el 12 de abril de 1907 como comedia en un acto (Díez Figueroa 2001).

${ }^{12}$ Según Fidel López Criado, "para el proletariado, la moral y el honor son un lujo incompatible con el hambre y la necesidad» (López Criado 2014: 131), idea que la obra escenifica con particular acierto. 
como meretriz. Viendo a Sebastiana ahogada por las deudas, la invita a pasar una noche con ella para conocer el mundo de la prostitución como posible alternativa a su pobreza. El espectador queda impactado al ver un cambio tan brusco entre los dos actos, ya que, como dice la acotación inicial, «los actos primero y segundo han de representarse con mutación, pero sin entreacto» (Linares Rivas 1999i: 1971). La habitación de la "Rabanitos» es una proyección de su personalidad: es una mujer vanidosa a la que le gusta aparentar posición social ("puesta con lujo»), pero a la que le es imposible llevar un tren de vida estable ("con desorden»).

El tercer acto se ambienta en «un gabinete de un restaurante de tono. En el centro una mesa en desorden, como después de terminada toda comida. Un par de ventanas al foro y una puerta a la izquierda» (Linares Rivas 1999i: 1992). El ambiente de la prostitución vuelve a estar asociado con el desorden y los excesos de la carne, en este caso, la comida. También pueden verse de nuevo las ventanas que habían desaparecido en la casa de la «Rabanitos». Es interesante ver la disposición de los personajes al empezar la escena primera de este acto:

Luz, a la ventana y apoyando la frente en los cristales, como si buscase que el frío disipase algo el calor del champagne: la Mimosa, Lulú y Pedro; en la otra ventana: doña Celestina, Jaime y Enrique; sentados a la mesa: la Rabanitos, Amparo y Tabardillo; sentados en un sofá: Becerra, de pie, solo, vuelto de espaldas (Linares Rivas 1999i: 1992).

De nuevo, Luz (pseudónimo de Sebastiana) está muy relacionada con la ventana. Si Sebastiana quisiera disipar el calor, lo lógico hubiera sido abrir la ventana, no pegarse contra el cristal. Sin embargo, ella no está preparada todavía para que entre el aire fresco del progreso. Lo mismo sucede con la «Mimosa», Lulú y Pedro. Las dos primeras son prostitutas sin posición social, secundarias, meros objetos de transacción. Pedro es un simple camarero. Quienes no están nada relacionados con las ventanas son, por un lado, las prostitutas fuertes, de prestigio, aquellas que dirigen el negocio, que son dońa Celestina, la «Rabanitos» y Amparo; por otro lado, los viciosos, los frívolos burgueses jóvenes cuyo único objetivo vital es la satisfacción de sus pulsiones más básicas, es decir, Jaime, Enrique, Tabardillo y Becerra. «Es de noche», el momento perfecto para desinhibirse, y, sin embargo, semánticamente opuesto al pseudónimo de Sebastiana, lo que indica que ella, en el fondo, no pertenece ni pertenecerá a ese mundo.

El acto cuarto abre con «la misma decoración del primero» (Linares Rivas 1999i: 2005). Es ahí donde Tabardillo, contradictorio, pero no hipócrita, aconseja a Sebastiana no entrar en el «negocio del amor». Esto aporta circularidad a la pieza y además permite dejar un final abierto. Tabardillo le da un buen consejo, pero ¿̨será suficiente como para solucionar los problemas materiales de Sebastiana? Y lo más importante, ¿̇será Sebastiana capaz de abrir en algún momento esas ventanas? Son preguntas que Linares Rivas sugiere a su público ${ }^{13}$.

13 En esta tipología también podría encajar Fausto y Margarita, tragicomedia en tres actos estrenada el 11 de abril de 1996, aunque se escribió en 1935. Su primer acto se ambienta en «una habi- 


\section{ESPACIOS SIMBÓLICOS}

Con esta etiqueta tan amplia se ha querido englobar aquellos espacios que Linares Rivas construye con la intención de que no parezcan extraídos de un referente real, sino de un mundo de fantasía mágico ${ }^{14}$. El ejemplo que aquí se analiza corresponde a una de sus obras más reconocidas: El caballero lobo, fábula en tres jornadas y en prosa, estrenada en el Teatro Espańol el 22 de enero de $1909^{15}$.

La jornada primera abre con «una cabaña con muebles rústicos. A la derecha foro, una ventana abierta por la que penetra un rayo de luna. En la ventana un cuervo. Forillo, árboles» (Linares Rivas 1999f: 1489). Linares Rivas ambienta la trama subordinante, en que la vieja cuenta el relato, en una cabańa propia de un ambiente rural, haciendo referencia al conocimiento popular transmitido entre generaciones a través de fábulas. Mientras en medio del ruido de las ciudades los ciudadanos están demasiado ocupados con frivolidades, en el campo siempre hay tiempo para los ritos ancestrales. De nuevo, vuelve a aparecer el símbolo de la ventana, esta vez abierta, que alude sin duda a la capacidad de los niños para cambiar el mundo. Pero al mismo tiempo, por la ventana «penetra un rayo de luna». Según el Diccionario de los simbolos, tiene que considerarse que la luna no tiene luz propia, depende del sol

tación alegre y clara, puesta un poco en estudio de pintor, con luz cenital, y adornado con tablas de pintura, grabados, figulinas y telas de colores vivos. Una mesatablero con cartones y tapices» (Linares Rivas 1999c: 333). Es la primera vez que Linares nos presenta una tienda bohemia como escenario. Ni siquiera se pierde su identidad en el segundo acto, cuando celebran la fiesta de la nueva temporada de moda: «una salita bien puesta [...]. Siendo habitación particular no deja de ser tienda [...]» (Linares Rivas 1999c:355). El color y la iluminación provocan una atmósfera alegre que contrasta con la oscuridad de La espuma del champagne. Fausto y Margarita se escribe en tiempos de la II República y el autor, que ya tenía problemas para seguir estrenando después de más de 30 años de éxito, afirma, con esperanza, que terminará la explotación del hombre por el hombre.

${ }^{14}$ Como afirma Emilio Peral Vega (2016), el teatro simbolista llega a España a través de Adrià Gual (1872-1943), inspirado, a su vez, por Edward Gordon Craig (1872-1966). Con ellos, se recupera la autoridad del director de escena y la importancia de algunos elementos como la iluminación, que abandonaba aquí su función realista para marcar una determinada iluminación al gesto del actor con el fin de exponer un conflicto interno. El caballero lobo fue capaz de llevar con gran éxito a escena esta corriente que, en la mayoría de los casos, estaba dirigida a una minoría.

15 Según Moisés Castro, El caballero lobo «es una pieza que, por su contenido, por su fondo, constituye una verdadera revelación en el panorama de la literatura española de principios de siglo. Linares supo reflejar en ella toda una serie de aspectos políticos, sociales y morales que, como hemos visto, son revolucionarios para su época» (Castro López 2000: 84). Y no solo supone una revelación en lo que respecta a sus posicionamientos ideológicos, sino también en lo estético. Según Cuesta Guadaño (2017), «es una de las piezas más representativas del teatro de animales [...] [y] se estrenó con éxito de público» (377). Al profesor le cuesta admitir la relevancia artística de esta obra, pues precede a Chantecler (1910), de Edmond Rostand (1868-1918), y, posiblemente, a L'Oiseau bleu (1908), de Maurice Maeterlinck (1862-1949), si damos credibilidad a las siguientes palabras del autor: "por el fondo que tiene El caballero lobo no la quiso representar ningún teatro y anduve ańos con la obra debajo del brazo» (Linares Rivas 1999b: 257). Esto convertiría a Linares Rivas en un visionario del teatro simbólico de animales europeo. Además, sería precedente de iniciativas teatrales españolas como el «Teatro de los niños» (1909), de Jacinto Benavente. 
para emitirla, y, también, que pasa por distintas fases. Por este motivo, «es símbolo de transformación y crecimiento" (Chevalier 1986, s. v. luna) ${ }^{16}$. Igualmente, aunque el cuervo se asocie de forma contradictoria en distintas culturas, por un lado, con la muerte, y por otro, con el nacimiento; en este caso concreto habría que interpretarlo de la siguiente forma: «siendo el negro el color del comienzo (el negro de la obra alquímica, la noche del seno materno y el surco recubierto de la tierra, etc.), el color negro asocia el cuervo con las operaciones de germinación y de fertilización» (Chevalier 1986, s. v. cuervo). El sol (la verdad) refleja en la luna (la fábula que contiene la verdad y transforma las mentes) y el cuervo (la vieja, la que germina las ideas) la transmite a los niños para que progrese la sociedad (ventana abierta).

La jornada segunda sucede «de día: en un bosque. A la izquierda, foro, una piedra blanca, en la que podrán sentarse» (Linares Rivas 1999f: 1496). El bosque es muy recurrente en diversas religiones paganas y precristianas como lugar de culto (Chevalier 1986, s.v.bosque). A su vez, la piedra es una proyección del alma (Chevalier 1986, s. v.piedra), cuyo color denota a los personajes que se sentarían encima. Lo curioso es que Linares Rivas no indica qué personajes deben sentarse ahí, por lo que podría deducirse que, tal y como Cordera traspasa el relato subordinado y se convierte en oyente de la historia de la anciana, también la anciana y los niños podrían trascender al relato subordinado como espectadores. Esto tendría sentido si consideramos la simbología del color blanco:

puede situarse en los dos extremos de la gama cromática. Absoluto y no teniendo otras variaciones que las que van de la matidez al brillo, significa ora la ausencia ora la suma de colores. Se coloca así ora al principio ora al final de la vida diurna y del mundo manifestado, lo que le confiere un valor ideal, asintótico (Chevalier 1986, s.v.blanco).

La conjunción entre los nińos (principio de la vida) y la anciana (final de la vida) proyecta un alma ideal (piedra blanca) sobre la cual asisten a la fábula dramatizada.

La tercera jornada sucede en «una explanada en la montaña. A foro derecha una cueva» (Linares Rivas 1999f: 1515). Entre muchos simbolismos, «la montaña

${ }^{16}$ La luna va sufriendo transformaciones a lo largo de la obra. Cuando la anciana empieza a contar el cuento, «desaparece el rayo de luna y queda la escena a oscuras» (Linares Rivas 1999f: 1492). Acto seguido, entra la Cordera a escena traspasando los límites del relato subordinado. Más adelante, al final de la escena XIV de la jornada segunda, «la escena, a oscuras, con un rayo de luna solamente; alumbra de derecha a izquierda» (Linares Rivas 1999f: 1510), justo después de que el Lobo rechazase las insinuaciones sexuales de la Gata. Por último, al final de la escena xv, «la luna ilumina la escena plenamente» (Linares Rivas 1999f: 1511) cuando la Mariposa se quema al intentar alcanzar la luz que tanto la atrae, el mismo destino que había sufrido su hermana. Esta transición podría corresponder a tres fases de la luna. Primero, la luna nueva, el momento más profundo de cambio, cuando las divinidades se acercan a la tierra durante la oscuridad de la noche. Segundo, la luna creciente, que se refiere al momento en que el Lobo se reafirma en sus principios morales. Tercero, la luna llena, cuando muere la Mariposa y el Lobo se vuelve consciente del fenómeno de la muerte. 
expresa también las nociones de estabilidad, inmutabilidad y a veces también de pureza. [...] De manera más general es a la vez el centro y el eje del mundo» (Chevalier 1986, s.v.montaña). A su vez, la cueva, "como arquetipo de la matriz materna, [...] figura en los mitos de origen, de renacimiento y de iniciación de numerosos pueblos» (Chevalier 1986, s. v.caverna). Esta jornada se centra, por un lado, en la supervivencia del amor entre Cordera y el señor Lobo. El amor se asocia con la montaña al ser creador de una familia estable fundamentada en bases humanas, y no en bases económicas o imperativos sociales. Por otro lado, se centra en el desarrollo personal del Lobato, su hijo. La cueva hace referencia a la condición del cachorro, que nace con aspecto de lobo, pero con corazón de cordero. Nunca podrá encajar en ninguno de los dos mundos y tendrá que aceptar sus diferencias para poder desarrollarse, siempre bajo el amparo de su familia ${ }^{17}$.

\section{ESPACIOS HISTÓRICOS}

No es común que las obras de Linares Rivas se ambienten en tiempos históricos lejanos al momento de su recepción. Sin embargo, hay que destacar que su primera obra estrenada de la que se tenga constancia, El amo de las Carolas (1890), también conocida como Las Carolas o Las Carolinas, se ambientaba en el siglo XviII ${ }^{18}$. Sin embargo, su obra histórica por excelencia es Lady Godiva, comedia en cuatro jornadas en verso, estrenada en el Teatro Español el 15 de enero de $1912^{19}$.

La jornada primera se ambienta «en el campo, con árboles. A foro, un trozo de muralla en ruinas. A derecha, un dosel a medio alzar». El trozo de muralla en ruinas alude a un desastre militar, mientras que el dosel a medio alzar indica un desastre político, que serán explicados en los cuatro primeros versos: «iDaos prisa! Os lo ruego... Y alzad pronto / las gradas y el dosel en las ruinas / de esa muralla antes que llegue el Duque... / (Irónico) que a honrarnos viene al invadir la villa» (Linares

${ }_{17}$ Linares Rivas también cultiva el simbolismo en Lo posible, juguete cómico en un acto y dos cuadros, estrenado en el Teatro Lara el 28 de marzo de 1905. Aunque el segundo cuadro representa un espacio burgués más fácil de ver en su producción, el primer cuadro muestra «el pasillo de los palcos plateas en el Real. De noche» (Linares Rivas 1918: 1). Aunque no se especifica, la trama sugiere que este primer cuadro debe parecer un sueńo para poder provocar la duda en el espectador durante el segundo cuadro, lo que dará pie a desarrollar conversaciones hilarantes. En este caso, es necesario tener en cuenta también que solo los dos protagonistas masculinos (Federico y Ricardo) van sin máscara. Asisten a una noche de carnaval donde todo es posible, que contrasta con las cadenas representadas por la estética del espacio burgués.

${ }_{18}$ El texto, actualmente, está perdido, pero algunas notas en prensa dejan saber que la obra trataba sobre la conquista de las Islas Carolinas por parte del Imperio espańol: «fue una pieza patriotera á [sic] que dió [sic] actualidad el incidente de las Islas Carolinas» (López Criado 1999: 185). La obra es un juguete en un acto y se estrenó en algún teatro de Madrid en 1890.

${ }_{19}$ Linares Rivas advierte al lector con una nota inicial que el argumento de esta obra se basa solo parcialmente en la famosa leyenda inglesa. 
Rivas 1999g: 1741). El escenario destruido permite presentar el conflicto de la trama nada más empezar la obra: la sanguinaria conquista de Coventry a manos del duque.

La segunda jornada sucede en «una cueva, que servirá de prisión, sin más luz que la de un ventano con barrotes de hierro" (Linares Rivas 1999g: 1761). Lo primero, es necesario retomar la simbología de la cueva que se había anotado con respecto a El caballero lobo: "como arquetipo de la matriz materna, [...] figura en los mitos de origen, de renacimiento y de iniciación de numerosos pueblos» (Chevalier 1986, s. v. caverna). Es ahí donde los prisioneros, y en especial lord Godiva, deben reflexionar sobre la muerte que les espera. Godiva, además, tendrá que abandonar, por un lado, sus prejuicios sobre la desnudez femenina; y por otro, su concepción machista según la cual la esposa forma parte del honor y de la honra del marido. La luz en la escena proviene de "un ventano con barrotes de hierro». Esta cavidad es por la que los prisioneros reciben información del exterior por parte de Jorge, carcelero amigo de los reos. La luz vuelve a asimilarse con la verdad.

La tercera jornada arranca en «una plaza, con el mayor número posible de practicables en puertas y ventanas. Es de noche, con Luna, pero discreta. Al foro un pasadizo de arcos en un palacio» (Linares Rivas 1999g: 1772). La plaza, por su amplitud, remarca la vergüenza que siente lady Godiva a aparecer desnuda. Los practicables, a su vez, indican la cantidad de gente que podría estar mirándola si incumpliesen su palabra. Debido al contexto de la escena, parece que la ventana, en este caso, tiene un sentido recto. La luna, como ya se había explicado, «es símbolo de transformación y crecimiento" (Chevalier 1986, s.v.luna). Lady Godiva transforma su mentalidad, se atreve a exhibir su cuerpo sin ropa y se convierte en una heroína para Coventry. Pero, además, la luna podría tener connotaciones eróticas. Linares Rivas hace que todos sus personajes no miren a lady Godiva al mismo tiempo que el espectador de la sala no puede dejar de mirar, convirtiéndolo en un voyeur. El pasadizo de arcos indica la lejanía de su destino e insinúa el largo camino que tendrá que recorrer.

La cuarta jornada abre en «una sala en el Monasterio de Coventry, con una gran ventana de vidrios de colores, al fondo. A fondo también, una puerta con tapices, lo mismo que una lateral a cada lado. Al lado de la puerta del foro, un sillón de cuero. Al lado de la ventana, una mesa larga con viandas» (Linares Rivas 1999g: 1782). Linares Rivas hace que su lady Godiva pasee desnuda por un monasterio medieval, lo que supone una blasfemia. Vuelven a aparecer las ventanas, esta vez sí asociadas a la necesidad de progreso, que no solo están cerradas (no entra el aire), sino que el sol (la verdad) se verá matizado por los vidrios de colores (mentalidad medieval). Las puertas con tapices, el sillón de cuero, la mesa larga y las viandas indican el poder económico y político de los que goza la Iglesia en Coventry ${ }^{20}$.

${ }^{20}$ En este apartado, aunque también muy cercana a los espacios simbólicos, se podría nombrar Toninadas, bufonadada heroica en un prólogo y tres jornadas, estrenada en el Teatro Español el 11 de febrero de 1916. Como se dice en la acotación inicial, «la acción de toda la obra en Algaria, país casi imaginario» (Linares Rivas 1916: 16). Sin embargo, sus espacios, a pesar de ser fantásticos, recuerdan épocas lejanas. La primera jornada se ambienta en «una sala de Palacio, que se supone 


\section{CONCLUSIONES}

En este trabajo se han analizado los espacios de algunas obras de Manuel Linares Rivas. El principal objetivo de la investigación era responder a las siguientes preguntas: ¿qué tipos de espacio presentan sus obras? ¿Hasta qué punto Linares Rivas transmite un compromiso social a través de la escenografía? Se han detectado seis espacios diferentes. En primer lugar, los espacios burgueses presentan salones modernos y prácticos propios de una nueva generación que rompe con la tradición. Concretamente en Cobardias (1919), el cambio entre el escenario aristocrático y el escenario burgués establece una alianza entre estos dos grupos sociales cuya consecuencia será la supervivencia de los males que destruyen la sociedad española anterior a la guerra civil. En segundo lugar, los espacios aristocráticos se caracterizan por sus muebles antiguos y ruinosos, su ambiente cargado y sombrío aferrado a la tradición. En La garra (1914), el espacio funciona como un condicionante de la acción de los personajes sin llegar a ejercer la tiranía propia del naturalismo. La tradición, encarnada en la Iglesia y en el Estado, pesa como una losa en la conciencia de sus personajes más conscientes de la cárcel en que todos se encuentran encerrados. En tercer lugar, los espacios rurales muestran muebles humildes, ambientación indeterminada y referencias a lo tradicional castellano. En La mala ley (1923), a través del juego temporal se realiza una crítica encubierta a la Iglesia. La alianza entre de la Hermida (burgués, terrateniente) y Dionisio (alta burguesía) no consigue solucionar el problema de fondo (la ley de herencias), aunque sí atajar el conflicto dramático más inmediato y personal.

Cuarto, los espacios populares son testigos de la pobreza, sin demasiados muebles y sin decoración prescindible. Quinto, el espacio simbólico no pretende ser un espejo para la realidad concreta, sino una proyección de un mundo mágico. En El caballero lobo (1909) se pone en tela de juicio el modelo decimonónico de familia, según el cual las decisiones de los hijos dependían del cabeza de familia. Atenta contra el decoro al representar de manera simbólica la cuestión sexual como un elemento de tradición popular para la enseńanza infantil. Aporta un punto de vista escandaloso para la moral de su tiempo hacia los cuentos tradicionales, tal y como habría hecho más tarde Bruno Bettelheim con su Psicoanálisis de los cuentos de hadas (1976). Por último, el espacio histórico viene determinado por castillos, ambientes exóticos, temas legendarios, etc. En Lady Godiva (1912) se presenta la cuestión de la sexualidad femenina y de su independencia hacia el varón, desmarcándose de la tendencia machista del honor y la honra. Godiva acaba siendo una heroína humillada

contigua a los salones en donde se celebra la recepción». La segunda en «el mesón de los Mirlos [...]. Mesas y taburetes. Al foro escalera practicable que conduce y termina en el primer piso [...]» (95). La tercera en "la pista de un circo en un barracón de feria» (197). Los espacios van degenerando, igual que el sistema monárquico que se critica en la pieza. Al principio era un orgullo (palacio), pero fue degenerando por los excesos burgueses (mesón), hasta lo que es en la actualidad, una auténtica bufonada (circo). Amalio Fernández (1859-1928) fue el encargado de pintar el escenario de manera que pareciese lo más realista y colorista posible. 
por los mirones, que no solo son aquellos personajes que entran en la escena final, sino también los propios espectadores. Se realiza un ataque a la Iglesia al poner una mujer exhibiendo su sexualidad dentro de un monasterio para el gozo del duque y sus secuaces, es decir, la nobleza, su clase social complementaria.

Los espacios burgueses de Linares Rivas se alejan de la propuesta de Joaquín Dicenta con Aurora (1902) y se aproximan a obras como Campo de armiño (1916), de Jacinto Benavente, en el aspecto minimalista de la descripción de la escena. Sin embargo, comparte la coherencia ideológica con Dicenta. Ambos describen un espacio burgués moderno, pero Benavente viste a través de él a sus personajes nobles de modernidad. De esta manera, los espacios aristocráticos de Linares Rivas se diferencian radicalmente de los supuestos del autor madrileńo, para quien el ambiente de la oligarquía no oprime. Asimismo, se aproxima a la escenografía que Valle-Inclán (1866-1936) diseña en Águila de blasón (1907), compartiendo el horror vacui y la claustrofobia. Con respecto a los espacios rurales, Linares se acerca a obras como $L a$ malquerida (1913), de nuevo, por la descripción minimalista de la escena; aunque sus espacios corresponden más al estrato social que pretende retratar Ángel Guimerá con Terra Baixa (1896). Sus espacios populares están lejos de parecerse a los de Daniel (1907), de Dicenta, que presenta un realismo muy minucioso y prefiere los ambientes obreros, mientras que Linares se centra en el trabajador autónomo de la ciudad. Por último, los espacios históricos distancian a Linares de Los intereses creados (1907) por su realismo que, a pesar de ser una farsa, igual que Toninadas (1916), no deja de ambientarse en una época lejana en el tiempo. Linares Rivas participa de la revolución escenográfica española, que tuvo como base la utilización de la luz eléctrica como elemento dramático (Peláez Martín 2003). Esto puede verse en obras como El caballero lobo, La garra, La espuma del champagne o Fausto y Margarita. Igualmente, algunas obras suyas, como Toninadas, contaron con Amalio Fernández para aportar un naturalismo ilusionista basado en una técnica colorista llamativa y novedosa para el espectador.

Hay que destacar también el uso metafórico que Linares Rivas da al signo de la ventana, presente en La mala ley, en La espuma del champagne, en El caballero lobo, en Lady Godiva, en Primero, vivir..., y en Mal año de lobos. Para el autor, la ventana abierta es un signo que indica el progreso, pues por ella entra el aire fresco, es decir, la nueva mentalidad; y el sol, es decir, la verdad. Una ventana cerrada es signo de un potencial para el cambio social que no se está aprovechando, porque se está viendo la verdad (el sol) y el paso del tiempo (aire), pero el personaje no participa de ello, se lo impide el cristal (su voluntad). Una ventana de colores indica que el personaje no puede acceder a la verdad de forma total debido a una desviación en su forma de entender el mundo (las vidrieras en Lady Godiva que simbolizan la regia moral impuesta por la Iglesia). Un espacio sin ventanas es agobiante y está condenado al fracaso, como termina sucediendo en Cobardías o en La garra.

Por todo lo expuesto, hay motivos suficientes para entender que el espacio en estas obras de Linares Rivas transmite un discurso rupturista con el sistema de alianzas entre la burguesía y la nobleza que había mantenido en pie la II Restauración borbónica. De esta manera, se podría considerar que Linares Rivas pertenece a la tendencia novadora del teatro español del primer tercio del siglo xx, a la cual 
pertenecen autores como Benito Pérez Galdós, Joaquín Dicenta o Ramón Gómez de la Serna. Todavía queda un largo camino por recorrer antes de poder afirmar con absoluta contundencia esta filiación. A fin de cuentas, Linares Rivas escribió 104 obras de teatro, 35 obras narrativas y una serie de artículos periodísticos aún sin clasificar, corpus inabarcable en estos momentos en que pocos somos los que investigamos su legado. No obstante, esta línea de investigación parece arrojar más frutos que aquella que afirma un supuesto oportunismo torpe todavía por demostrar para justificar su enorme éxito en taquilla y en crítica.

Recibido: septiembre de 2010; ACEPTADo: abril de 2021 


\section{BIBLIOGRAFÍA}

Aub, Max (1974): Manual de historia de la literatura española, Madrid: Akal.

Berenguer, Ángel (1982): «El teatro en el siglo xx (hasta 1936)», en José María Díez Borque (ed.), Historia de la literatura española, Madrid: Taurus, vol. 4, 7-87. Primera edición en 1980.

Brown, Gerald (1974): Historia de la literatura española. Siglo XX, Barcelona: Ariel. Publicación original: Brown, Gerald (1972), A Literary History of Spain. The Twentieth Century, New York: Barnes and Noble.

Castaño Penalva, Máximo (2015): «La visión reformista sobre la mujer y el divorcio en la obra de un dramaturgo de éxito en el primer tercio del siglo xx: el diputado conservador Manuel Linares Rivas", Revista Historia Autónoma, 6, 61-74.

Castro López, Moisés (2000): "Planteamientos sociales en El caballero lobo, de Linares Rivas», en Eva Candia Pérez et al., Actas. I Congreso estudiantil de literatura española contemporánea, A Coruña: Universidade da Coruña, 81-84.

Castro López, Moisés (2008): «La vida teatral en A Coruńa y biografía de M. Linares Rivas. 1902: El Noroeste (2. ${ }^{\circ}$ cuatrimestre)», en Moisés Castro López et al., Haz de luz. Estudios de literatura contemporánea, A Coruña: Universidade da Coruña, 159-169.

Chevalier, Jean y Alain Gheerbrant (1986): Diccionario de los simbolos, Barcelona: Herder.

Cuesta Guadaño, Javier (2017): El teatro de los poetas. Formas del drama simbolista en España (18901920), Madrid: CSIC.

Díez Figueroa, Rebeca (2001): «La espuma del champagne, de Linares Rivas: dos maneras de hacer teatro", en Fidel López Criado (ed.), El papel de la literatura en el siglo XX. I Congreso Nacional Literatura y Sociedad, A Coruña: Universidade da Coruña, 295-311.

Díez FigueroA, Rebeca (2005): «Mujer, progreso y república en el teatro de Manuel Linares Rivas», en Fidel López Criado (ed.), La república de las letras y las letras de la república. Estudios de literatura española contemporánea, A Coruña: Ayuntamiento de A Coruńa, 205-210.

García Freire, Ana María (2009): «La heroicidad femenina en el teatro de Manuel Linares Rivas», en Fidel López Criado (ed.), Héroes, mitos y monstruos en la literatura española contemporánea, Santiago de Compostela: Andavira, 87-94.

García López, José (1962): Historia de la literatura española, Barcelona: Vicens Vives.

Huerta Calvo, Javier y Emilio Peral Vega (2003): «Benavente y otros autores», en Javier Huerta Calvo (ed.), Historia del teatro español, Madrid: Gredos, vol. 2, 2271-2310.

Linares Rivas, Manuel (1916): Toninadas, Madrid: Hispania.

Linares Rivas, Manuel (1918): Lo posible, Madrid: La Novela Cómica.

Linares Rivas, Manuel (1919): Cobardias, Madrid: Hispania.

Linares Rivas, Manuel (1921): «Manuel Curros Enríquez», en Discursos leidos ante la Real Academia Española en la recepción pública del Excmo. Sr. D. Manuel Linares Rivas el día 15 de mayo de 1921, Madrid, Imprenta de Vicente Rico. URL: <https://bit.ly/2HOohow> (última consulta: $17 / 09 / 2020$ ).

Linares Rivas, Manuel (1927): La mala ley/Primero vivir..., Madrid: El Teatro Moderno.

Linares Rivas, Manuel (1928): En cuarto creciente/El señor Sócrates, Madrid: El Teatro Moderno, 6-34. 
Linares Rivas, Manuel (1999a): «Intimidades de teatro», en Fidel López Criado, El teatro de Manuel Linares Rivas, A Coruña: Diputación de A Coruña, vol. 1, 221-243.

Linares Rivas, Manuel (1999b): «Los cómicos, los autores y quien los hace andar a todos de cabeza», en Fidel López Criado, El teatro de Manuel Linares Rivas, A Coruña: Diputación de A Coruña, vol. 1, 245-263.

Linares Rivas, Manuel (1999c): Fausto y Margarita, en Fidel López Criado, El teatro de Manuel Linares Rivas, A Coruña: Diputación de A Coruña, vol. 1, 329-388.

Linares Rivas, Manuel (1999d): El camino de la gloria, en Fidel López Criado, El teatro de Manuel Linares Rivas, A Coruña: Diputación de A Coruña, vol. 2, 921-967.

Linares Rivas, Manuel (1999e): Aire de fuera, en Fidel López Criado, El teatro de Manuel Linares Rivas, A Coruña: Diputación de A Coruña, vol. 2, 1066-1118.

Linares Rivas, Manuel (1999f): El caballero lobo, en Fidel López Criado, El teatro de Manuel Linares Rivas, A Coruña: Diputación de A Coruña, vol. 2, 1485-1538.

Linares Rivas, Manuel (1999g): Lady Godiva, en Fidel López Criado, El teatro de Manuel Linares Rivas, A Coruña: Diputación de A Coruña, vol. 3, 1737-1797.

Linares Rivas, Manuel (1999h): La garra, en Fidel López Criado, El teatro de Manuel Linares Rivas, A Coruña: Diputación de A Coruña, vol. 3, 1915-1965.

Linares Rivas, Manuel (1999i): La espuma del champagne, en Fidel López Criado, El teatro de Manuel Linares Rivas, A Coruña: Diputación de A Coruña, vol. 3, 1969-2011.

Linares Rivas, Manuel (1999j): Mal año de lobos, en Fidel López Criado, El teatro de Manuel Linares Rivas, A Coruña: Diputación de A Coruña, vol. 3, 2303-2361.

López Criado, Fidel (1999): El teatro de Manuel Linares Rivas, A Coruña: Diputación de A Coruña, 3 vols.

López Criado, Fidel (2009): «La mitología progresista en el teatro social español de primer tercio del siglo Xx», en Fidel López Criado (ed.), Héroes, mitos y monstruos en la literatura española contemporánea, Santiago de Compostela: Andavira, 27-40.

López Criado, Fidel (2014): «La ley, la moral y el decoro en el teatro feminista del primer tercio del siglo XX», Acta literaria, núm. 48, 117-137.

Mainer, José Carlos (2010): Historia de la literatura española. Modernidad y nacionalismo (19001936), Barcelona: Crítica.

Peláez Martín, Andrés (2003): «El arte escénico en la Edad de Plata», en Javier Huerta Calvo (ed.), Historia del teatro español, Madrid: Gredos, vol. 2, 2201-2238.

Peral Vega, Emilio (2016): «Dos visionarios en escena: Edward Gordon Craig y Adrià Gual», Hispanic Research Journal: Iberian and Latin American Studies, núm. 6, 489-503.

Rodríguez CaCho, Lina (2009): Manual de historia de la literatura española 2. Siglos XVIII al XX [hasta 1975], Madrid: Castalia.

Rodríguez López-VÁzQuez, Alfredo (1995): «La trilogía del adulterio de Linares Rivas: notas para una didáctica del teatro breve», Lenguaje y textos, núm. 6-7, 27-40.

Ruiz Ramón, Francisco (1986): Historia del teatro español. Siglo XX, Madrid: Cátedra.

Villarías Zugazagoitia, José María (2001): «El polémico estreno en Madrid de La garra», Letras de Deusto, vol. 31, núm. 90, 103-125. 
